NBER WORKING PAPER SERIES

UNIVERSITY ENTREPRENEURSHIP AND PROFESSOR PRIVILEGE

Erika Farnstrand Damsgaard

Marie C. Thursby

Working Paper 17980

http://www.nber.org/papers/w17980

\author{
NATIONAL BUREAU OF ECONOMIC RESEARCH \\ 1050 Massachusetts Avenue \\ Cambridge, MA 02138 \\ April 2012
}

Financial support from the Torsten and Ragnar Söderberg Foundations and Jan Wallander's Research Foundation is gratefully acknowledged. We thank participants of the June 2011 IFN/Swedish Entrepreneurship Forum Conference Entrepreneurship, Industrial Development and Growth for helpful comments and suggestions. Thursby acknowledges funding from the National Science Foundation (Sub-award 44771-7471 of Award 0335765 and Award 0965289. The views expressed herein are those of the authors and do not necessarily reflect the views of the National Bureau of Economic Research.

NBER working papers are circulated for discussion and comment purposes. They have not been peerreviewed or been subject to the review by the NBER Board of Directors that accompanies official NBER publications.

(C) 2012 by Erika Farnstrand Damsgaard and Marie C. Thursby. All rights reserved. Short sections of text, not to exceed two paragraphs, may be quoted without explicit permission provided that full credit, including $\odot$ notice, is given to the source. 
University Entrepreneurship and Professor Privilege

Erika Farnstrand Damsgaard and Marie C. Thursby

NBER Working Paper No. 17980

April 2012

JEL No. O3,O33,O34

\begin{abstract}
This paper analyzes how institutional differences affect university entrepreneurship. We focus on ownership of faculty inventions, and compare two institutional regimes; the US and Sweden. In the US, the Bayh Dole Act gives universities the right to own inventions from publicly funded research, whereas in Sweden, the professor privilege gives the university faculty this right. We develop a theoretical model and examine the effects of institutional differences on modes of commercialization; entrepreneurship or licenses to established firms, as well as on probabilities of successful commercialization. We find that the US system is less conducive to entrepreneurship than the Swedish system if established firms have some advantage over faculty startups, and that on average the probability of successful commercialization is somewhat higher in the US. We also use the model to perform four policy experiments as suggested by recent policy debates in both countries.
\end{abstract}

Erika Farnstrand Damsgaard

Research Institute of Industrial Economics

Box 55665

SE-102 15 Stockholm, Sweden

erika.farnstrand.damsgaard@ifn.se

Marie C. Thursby

College of Management

Georgia Institute of Technology

800 West Peachtree Street, NW

Atlanta, GA 30308-1149

and NBER

marie.thursby@mgt.gatech.edu 


\section{University Entrepreneurship and Professor Privilege}

University entrepreneurship, whether defined broadly as commercialization of faculty inventions or more narrowly, in terms of faculty founding companies to develop their inventions is subject to considerable debate in both academic and policy communities. While it is widely accepted that university research is a critical part of national innovation systems, the participation of university faculty in industrial application of their research is often questioned. Much of the debate surrounds the trade-off between the importance of the inventor's tacit knowledge in further development and the cost of diverting faculty from more basic duty within the university (Thursby and Thursby 2010). More fundamentally, some question the ownership of faculty inventions, suggesting that faculty, rather than the university, should own their inventions, the so-called professor privilege (Litan, Mitchell, and Reedy 2008, Kenney and Patton 2009).

In this paper, we examine two institutional regimes: one with university ownership, as is the case in the United States, and the other with professor privilege, as in Sweden. We compare the mode of commercialization chosen (entrepreneurship versus license to established firms) and the success of commercialization under each regime. An important difference between the two regimes lies in the identity of the agent deciding whether to commercialize an invention by licensing to the faculty inventor or by licensing to an established firm. In the US system, it is the technology transfer office (TTO), and in the Swedish system, it is the faculty inventor herself. Naturally, the two agents have different objective functions, and therefore, optimal decisions differ. In addition, there is an principal-agent problem inherent in university ownership. That is, with university ownership, income from commercialization is shared between the university and the inventor, creating an agency problem not present under professor privilege since the inventor has no obligation to share income. This distinction yields important differences when inventions licensed require further inventor effort, as is the case for most university inventions. Lastly, there could be differences in the ability of universities and inventors to find licensees. We develop a theoretical model that allows us to examine commercialization under the two systems, and which is rich enough to take the differences described above into account. The richness of the model implies that we must resort to numerical solutions, and we solve the model for a wide range of parameter values.

One of the main findings is that the US system is less conducive to entrepreneurship than the Swedish system, if established firms have some advantage over faculty startups. The reason is that the inventor can collect, on average, a larger share of revenues when she starts a firm, and therefore chooses the startup more often although the established firm has some advantage. We also find that on average, the probability of successful commercialization is somewhat higher in the US. However, if there are search costs in finding an established firm, if the inventor prefers basic research or if there are close to constant returns to scale in development effort, and any of the three is combined with a general advantage for the established firm, then the average probability of commercialization success is instead higher in Sweden.

A higher probability of commercialization success in the US is generally a result of the fact that the 
TTO chooses to license to an established firm which has an advantage in commercialization skills, whereas the inventor prefers the startup. In the instances where the probability of successful commercialization is higher in Sweden, it is due to the fact that when both agents choose to license to an established firm, the agency problem present in the US implies that the inventor exerts less effort.

We then use the model to perform four policy experiments as suggested by recent policy debates in both countries. We find that an internet based system for finding licensees among established firms reduces commercialization through startups, and has a positive effect on the probability of successful commercialization. We also find a somewhat counterintuitive effect of a new policy used in select US universities to promote entrepreneurship; that the expedited startup license (often referred to as the "Carnegie License") reduces commercialization through startups, but the effect on successful commercialization is mixed. If the TTO has an advantage in finding a licensee among established firms compared to the inventor, the probability of successful commercialization is always higher in the US than in Sweden. Lastly, if the TTO has a disadvantage compared to the inventor, the probability of successful commercialization can be higher in Sweden than in the US. This occurs when established firms have some advantage over faculty startups.

The rest of the paper is organized as follows. Section 2 describes the policy environment in the US and in Sweden. Section 3 sets the stage for policy comparisons, and Section 4 presents the model. In Section 5 , a baseline version of the model is presented, which illustrates the differences across systems. Section 6 compares the two systems in the full model, and Section 7 contains a robustness analysis of the results. The policy experiments are described in Section 8, and Section 9 concludes.

\section{The Policy Environment}

Until recently, professor privilege was common among European countries, with Swedish university faculty having this right as an exception to the 1949 Act on the Rights to Employee's Inventions designating employer ownership. While professor privilege remains in Sweden and became the policy in Italy in 2001, within the last decade Denmark, Finland, Germany, and Norway all changed to university ownership models similar to the Bayh Dole Act of 1980 which gives US universities the right to own inventions from publicly funded research. Between 2004 and 2009, the Swedish government formally considered the possibility of university ownership, but ultimately decided against adoption (SOU 2005:95, Government Bill 2008/2009:50).

In Asia, adoption of Bayh-Dole type legislation has become increasingly prevalent. Japan, for example, changed from a model in which inventions were owned by either the inventor or the nation to one in which university employers can take ownership (OECD). In other Asian countries, such as Malaysia, a shared ownership model has become prevalent (Stephen 2010). 
Somewhat ironically, the proliferation of movements toward university ownership outside the United States came at a time of growing skepticism about Bayh Dole in US academic and policy circles. Some doubted that policies which worked well in the United States would translate to other countries, particularly those where professors historically owned their inventions, cautioning that the counterfactual to university ownership in the US was government ownership and free license of federally funded inventions (Mowery and Sampat 2005). Others were critical of the US system, per se. Criticisms ranged from the view that patent licensing threatened the pursuit of basic research to the opposing view that the infrastructure that had evolved under Bayh-Dole stifled entrepreneurial effort (Greenburg 2007, Thursby and Thursby 2010). In the popular press, universities were accused of acting like profit centers, but serious academics also questioned whether the patent system was interfering with widespread dissemination of publicly funded research (Murray and Stern 2007, Washburn 2008). There were also critics in industry, where a common view was that university technology transfer offices (TTOs) were difficult to deal with, not only in licensing publicly funded research, but also the terms under which industry would license results of industry sponsored research (Thursby and Thursby 2003).

Amidst the US debates, Litan et al. (2008) proposed several alternatives. One alternative would maintain university ownership, but would give faculty "free agency" to choose to license their inventions through their TTO or to select another agent. The most extreme alternative proposed was, in fact, professor privilege, in which case Litan et al. argued universities would benefit because "loyal" faculty who profited from their inventions were likely to donate back to the university. A third proposal pertained primarily to small universities. The recommendation was for TTOs to form alliances, which would allow bundling of inventions across universities as well as access to commercialization personnel with superior expertise. The fourth proposal, addressing the need for wide dissemination, was for TTOs to make use of internet-based marketing mechanisms, such as the iBridge network (Litan et al. 2008).

In the face of this controversy, two committees of the National Research Council (NRC) commissioned a National Academies (NAS) review of the organization and functioning of university technology transfer under Bayh Dole. The study culminated in a set of research findings and recommendations put forth in Merrill and Mazza (2010).

The scenarios we examine are motivated by the Swedish and US policy initiatives. Both focus on professor privilege versus university ownership, albeit from opposite perspectives: professor privilege the status quo in Sweden and university ownership in the US. In both, the status quo was the winning recommendation. Importantly, however, these decisions were supported by statements of insufficient evidence to support a change. For example, NAS study cited only one comparison of the Swedish and US cases, which failed to show an advantage to the Swedish system (Goldfarb and Henrekson 2003). With the lack of systematic evidence the NAS examining committee saw no reason to recommend a change. 


\subsection{SOU 2005:95}

In 2004, the Swedish government commissioned an analysis of professor privilege in response to discussion of the 'Swedish paradox.' Although Sweden was a world leader in R\&D investment relative to gross domestic product (GDP), its growth lagged the average for OECD countries. The country was a leader in terms of patents and scientific publications per capita, which should have positioned it well for entrepreneurial led growth (Braunerhjelm 2007). In principle, professor privilege should provide university employees the necessary incentives to commercialize their inventions.

The Inquiry considered many issues related to commercialization of university inventions, those most relevant for our study are surrounding the ownership and reporting of university inventions. The report, SOU 2005:95, proposed two potential changes to Swedish higher education policy: mandatory reporting of inventions and institutional takeover of ownership. Under mandatory reporting professor privilege would be maintained, but employees with research duties in institutions of higher education would be required to report any inventions resulting from their research. They could, in principle, make arrangements for the institution to take over rights to the invention, but such arrangements would be purely voluntary. Under the second alternative, the 'teacher's exception' to the 1942 Employee's Invention Act would be abolished. Institutions of higher education would be entitled to takeover their employees' inventions in return for reasonable compensation. In the event of institutional takeover, the employer should take effective measures toward commercialization, including applying for patent protection. If such measures were not taken, the employee would have the right to recover the invention or to receive appropriate compensation if the employer had sold the rights.

The 2008/2009:50 government bill acknowledged the SOU 2005:95 proposals, but nonetheless asserted the importance of professor privilege. In maintaining the privilege, the bill stressed the importance of professor privilege in providing the incentives for researchers to commercialize their inventions. Without adequate university systems for commercialization and mechanisms to ensure adequate incentives for researchers to take part in the process, the privilege should be maintained.

\subsection{US National Academies' Study}

The 2010 National Academies' study was a comprehensive review by a Committee on Management of University Intellectual Property. With thirty years of experience since the passage of Bayh Dole, a systematic review was feasible and needed in light of growing controversy. Six findings and fifteen recommendations came out of the study (Merrill and Mazza 2010, Ch. 4).

The Committee found that: (i) the first goal of university technology transfer is wide dissemination of university-generated research, (ii) effective transfer can occur in multiple ways, (iii) university ownership is superior to its predecessor in the US, i.e., government ownership, (iv) there is little evidence that university practices have undermined academic norms, (v) a persuasive case has not been made for "free 
agency," and (vi) proposals to "empower" university faculty by giving them ownership of their inventions reflect perceived underappreciation of the need to engage faculty in the process.

Many of the Committee's recommendations were aimed at improving organizational efficiency, making goals more transparent and publicly oriented, and ensuring widespread use of research tools. The recommendation most relevant to our analysis is the 10th, which was designed to promote practices to support entrepreneurial ventures by university faculty, staff, or students. The foremost recommendation was the adoption of standardized procedures and license terms to expedite startup formation.

\section{Setting the Stage for Policy Comparisons}

Three themes pervade the policy discussions. First, despite an extensive literature on university technology transfer and entrepreneurship, there is little systematic analysis of the Swedish and US systems. Second, a critical difference in the ownership schemes is 'who' determines the path to commercialization. Is it the professor who decides whether her inventions merit commercial development and, if so, the best route to commercialization? Or is it the university TTO who makes these decisions? Finally, without systematic study, we understand little about the likelihood of commercialization under the two systems, or even the likelihood of different modes of commercialization (i.e., is entrepreneurship or licensing to established companies). In this section, we set the stage for an analysis of the second and third themes by reviewing the conceptual issues and related prior work.

\subsection{The Arguments for University Ownership and Professor Privilege}

The arguments for university and inventor ownership, though quite distinct, are both inextricably linked with the embryonic nature of university inventions. Indeed prior to the passage of Bayh Dole in 1980, proponents argued that firms would not license and develop the basic inventions resulting from federally funded research (Rai 1999, Mowery et al. 2004). Such inventions required substantial and risky development before commercial application. With federal government retention of rights and free, nonexclusive license any rents associated with commercialization would be easily dissipated. Thus it was not the university ownership, per se, of Bayh Dole that was the crux of the argument, but the ability of the owner to exclusively license. In principle, allowing inventor ownership along with the right to exclusively license would have been another solution.

Although it was not a part of the rationale for Bayh Dole, a share of license revenue for the inventor was among the requirements of the Act. It was only later that survey evidence indicated the importance of inventor effort for commercial development of many inventions. A 1996 survey of US universities indicated that $45 \%$ of the inventions they licensed were only a proof of concept when they were licensed, with another $37 \%$ no more than a lab scale prototype. The view of the technology transfer personnel executing the licenses was that three fourths of these would need inventor effort for commercial application (Thursby 
et al. 2001). This is consistent with survey evidence from business executives involved in licensing US university inventions. In their estimation, three fourths of the inventions they licensed were no more than a lab scale prototype at the time of license, and for $55 \%$ of these licenses, they engaged the inventor in the development process. They engaged the inventor much less for inventions ready for the market, but these inventions represented only 7\% of their licenses from universities (Dechenaux et al. 2011).

The rationale for the inventor to share license revenue when the university owns the invention is much the same as the argument for professor privilege. However, the form of the revenue matters (Jensen and Thursby 2001; Dechenaux et al. 2011). There is a moral hazard problem with regard to inventor effort since the inventor may well prefer to spend time conducting research in her lab than spending time in development with the licensee. One way to solve the problem is to specify fees contingent on success such as milestones after technical success, royalties, or equity.

The important point vis-à-vis professor privilege, however is that for any given positive sum of contingent payments, inventor effort is increasing in the share. For a given payment structure, the optimal share from the point of view of inventor effort is one, which is equivalent to the solution of selling the project to a risk neutral agent in the classic principal agent or agency problem (Laffont 1989). Thus, with respect to inventor effort, professor privilege weakly dominates university ownership, ceteris paribus. The issue, however, is not that simple since this simple comparison abstracts from any differences in the ability of inventors and universities to obtain licensee interest or financing (Henrekson and Rosenberg 2001).

\subsection{University Ownership and the Role of Technology Transfer Offices (TTOs)}

University ownership of inventions along with a dedicated TTO might dominate a system of professor privilege for a variety of reasons. Several theoretical studies focus on the potential for TTOs to act as intermediaries between inventors and potential licensees (Hoppe and Ozdenoren 2005, Macho-Stadler et al. 2007, Hellmann 2007). In all three cases, these offices serve to mitigate the uncertainty surrounding university inventions.

In Hoppe and Ozdenoren (2005) uncertainty about the profitability of inventions prevents firms from licensing them unless a TTO invests in acquiring information to reduce this uncertainty. They examine equilibria in which it is worthwhile for the TTO to make this investment and for firms to adopt and invest in developing inventions. The authors show that the use of success-based payment terms, such as royalties or equity signals to firms that the TTO is interested in choosing the best match of inventions with firms. When the number of inventions available to the TTO is sufficiently high, these payments support an equilibrium in which the TTO performs an intermediary function. Macho-Stadler et al. (2007) is similar in that firms have incomplete information about invention quality and contracts take the form in which universities receive a share of licensee profits. The TTO, with private information about true invention quality, may shelve a portion of the inventions in order to establish a reputation for offering high-quality 
inventions. As in Hoppe and Ozdenoren, whether it is worthwhile for the TTO to invest in establishing such a reputation depends on a sufficient supply of inventions.

Both of these studies point to potential TTO benefits that are unlikely to be seen under professor privilege. On the other hand, neither study addresses issues related to inventor incentives to disclose inventions to the TTO or to cooperate in further development. One of the major concerns expressed by proposals for alternatives to university ownership was that because of conflicting objectives, TTOs in practice have difficulty getting faculty inventors to disclose their inventions (Kenney and Patton 2009; Litan et al. 2008). Survey evidence also points to conflicting objectives between TTOs and faculty inventors (Thursby et al. 2001).

Hellmann (2007) examines the role of patents in a model where scientists (inventors) are unaware of which firms can use their discoveries and firms are unaware of which academic discoveries would be useful to them. Central to the model is a costly matching process in which inventors and firms find each other. If a match is successful some portion of firm profits are transferred to the inventor. The existence of a patent raises the transfer payment to the inventor. He shows that patents increase the incentive for inventors to search for firms that could use their discoveries, but dampen the incentive for firms to search for discoveries made outside their own laboratories. This is akin to the effect found by Valentin and Jensen (2007) in their study of Denmark and Sweden. Nonetheless, Hellmann's model provides a justification for delegating searches for compatible firms to a TTO which may be more efficient at searching than the inventor. Again, however, critics of the US system in practice claim that inventors often have better information than the TTO (Kenney and Patton 2009), and TTOs themselves report that faculty inventors are one of their best sources of information about licensees.

One aspect of TTO performance which appears to have been largely overlooked is the extent to which TTOs license inventions to startups versus established firms. Statistics from the Association of University Technology Managers (AUTM) routinely show that the overwhelming majority of licenses are to established firms. As reported in Jensen and Showalter (2011) startup licenses represent little more than $10 \%$ of licenses executed, which seems somewhat counterintuitive given their embryonic nature. This, combined with the discrepancy between TTO and inventor objectives, it seems unlikely that a system of university ownership would yield the same result in terms of licenses to startups as would a system of professor privilege.

While university entrepreneurship has been extensively researched (Rothaermel et al. 2007), there is little understanding of the relative merits of commercialization through faculty startups versus established companies. Indeed much of the analysis of startups has been empirical and has focused on US data (DeGregorio and Shane 2003, Lowe and Ziedonis 2006, Thursby, Fuller, and Thursby 2009). The advent of Bayh-Dole type legislation in Europe, along with the European Paradox has motivated a number of European studies, but these tend to focus on patents rather than startups (Geuna and Nesta 2006, Lissoni et al 2009, Valentin and Jensen 2007, Verspagen 2006). To our knowledge, Jensen and Showalter (2010) is 
the only theoretical analysis of the choice between a startup and established firm and their model is one of university ownership. They focus on a technology transfer office's choice between licensing to a startup versus an established firm as a function of inventor and university characteristics. Macho-Stadler et.al (2008) examine licenses to spin-offs, but as does much of the literature, focuses on optimal contract terms. Conti (2009) is the only theoretical model in which the faculty member makes a choice. The decision she considers is which fields of use a professor would be willing to assign to a research sponsor. None of these studies compare university ownership and decision making with professor privilege.

\section{A Model of Commercialization under the Alternative Systems}

In this section we develop a theoretical model that allows us to examine commercialization under the two systems. Commercial application of the invention requires further development, the success of which is uncertain. As with many university inventions, the discovery is sufficiently embryonic that it requires further technical and market development. For the technical development, the inventor's effort is required. This is consistent with data from US universities showing that three quarters of the inventions licensed are no more than a proof of concept or lab-scale prototype and for these inventions technical development requires inventor involvement more than half of the time (Jensen and Thursby 2001, Dechenaux et al. 2010). For such early stage inventions, the ultimate use may even be uncertain, and even when applications are clear, market success if uncertain (Shane 2000). In addition, Braunerhjelm and Svensson (2010) show, using a dataset on patents granted in Sweden, that when the patent is licensed to an established firm, profits are higher if the inventor is involved in the commercialization process. They conclude that the inventor is important for further adaptation of the innovation and to reduce uncertainty.

Our model is a stylized description of the Swedish and US systems. In our model of the US system, the technology transfer office (TTO) of the university decides whether to license the invention to the faculty inventor or to an established firm. In either case, the inventor's effort is required for further development. We restrict our attention to inventions with positive expected profits from development and commercialization effort, so that once the TTO determines the licensee, the inventor chooses the amount of time to spend on development. In our model of the Swedish system, the professor chooses whether to license to an established firm or attempt to commercialize her invention in a startup company. We assume the faculty member remains in the university regardless of the commercialization mode, so that her university responsibilities act as a constraint on the time she can devote to development, regardless of the system or mode of commercialization.

The inventor's development effort under each mode of commercialization (US and Swedish) is determined to maximize her expected utility. We adopt the conventional view that she derives utility from income as well as her basic research. For simplicity, we adopt the following log linear function of these 
two elements:

$$
U_{i}^{j}=\ln \left(I_{i}^{j}\right)+A \ln \left(T-\gamma e_{i}^{j}\right)
$$

where $i \in\{S, F\}$ denotes startup and established firm, respectively, and $j \in\{U S, S W E\}$ denotes the US and Sweden, respectively. $A$ gives the relative weight on the income and basic research parts of utility, $I_{i}^{j}$ is the inventor's total income, and $T$ is total time available for basic research. Thus, her development effort, $e_{i}^{j}$, has disutility because it reduces the time she can spend on basic research projects. The parameter $\gamma$ scales the development effort.

The optimal level of effort under each commercialization mode affects the probability that the invention will be successfully commercialized, which in turn will affect the mode chosen by the relevant decision maker in the licensing decision (i.e. the TTO in the US case and the inventor in the Swedish case). More specifically, we assume the probability of technical success, or the development probability is given by

$$
\begin{aligned}
p\left(e_{i}^{j}\right) & =B\left(e_{i}^{j}\right)^{\lambda} \\
\lambda & <1
\end{aligned}
$$

reflecting the fact that inventor effort is necessary. The probability that the invention is successfully commercialized (i.e. that it makes it to the market) depends on this probability and the probability that the licensee successfully markets it. Thus, we define the probability of successful commercialization as

$$
P=p\left(e_{i}^{j}\right) q_{i}
$$

where $q_{i} \in(0,1)$ is the probability that the developed product gets sold on a market. It is intended to capture general commercialization skills that are independent of the invention itself. Therefore, we will refer to $q_{i}$ as commercialization skills, which are specific to the established firm, and to the startup, respectively. Expected profits from commercialization of the invention are then given by:

$$
\Pi_{i}^{j}=B\left(e_{i}^{j}\right)^{\lambda} q_{i} \pi-c
$$

where $\pi$ is product market profit and $c$ is a fixed development cost.

In the following discussion we summarize the choice of commercialization mode under the two systems. A formal representation of the choice under the two systems is given in the Appendix.

\subsection{The US System}

There is considerable evidence that in the US one of the primary objectives of TTOs is to maximize license income (Thursby et al 2001; Jensen and Thursby 2001). Accordingly, we assume the TTO chooses a licensee so as to maximize its expected license revenue. In general, we assume this revenue is a royalty payment based on the licensee's net sales. We treat the royalty rate as exogenous and, assume the TTO cannot discriminate in the rate it charges to different licensees. If it licenses to the inventor, it bears no 
cost, but if it licenses to an established firm it bears a search cost. According to Bayh-Dole, the TTO is required to share a portion of this revenue with the faculty inventor, which we denote by $\alpha$.

Expected license revenue to the TTO if it licenses to an established firm is given by

$$
R_{F}=(1-\alpha) r_{F}^{U S}\left(B\left(e_{F}^{U S *}\right)^{\lambda} q_{F} \pi\right)-v k
$$

where $(1-\alpha)$ is the TTO's share of license revenue, $r_{F}^{U S}$ is royalty rate, $e_{F}^{U S *}$ is optimal inventor effort, $k$ is search cost for an individual researchers of finding a firm, and $v$ is the share of the cost that the TTO incurs. If the TTO has increasing returns to scale in searching, informational advantages or skills, that corresponds to $v<1$. The optimal effort level chosen by the inventor is given by

$$
e_{F}^{U S *}=\arg \max _{e_{F}^{U S}}\left(\ln \left(s^{U S}+\alpha r_{F}^{U S}\left(B\left(e_{F}^{U S}\right)^{\lambda} q_{F} \pi\right)\right)+A \ln \left(T-\gamma e_{F}^{U S}\right)\right)
$$

where $s^{U S}$ is her university salary in the US.

Expected license revenue to the TTO if the licensee is a startup is

$$
R_{S}=(1-\alpha) r_{S}^{U S}\left(B\left(e_{S}^{U S *}\right)^{\lambda} q_{S} \pi\right)
$$

where $e_{S F}^{U S *}$ is optimal inventor effort in her own startup.

The TTO chooses to license to a startup if

$$
R_{S}>R_{F}
$$

or, defining $\Omega$ as:

$$
\Omega=(1-\alpha) r_{S}^{U S}\left(B\left(e_{S}^{U S *}\right)^{\lambda} q_{S} \pi\right)-(1-\alpha) r_{F}^{U S}\left(B\left(e_{F}^{U S *}\right)^{\lambda} q_{F} \pi\right)+v k
$$

the condition can be stated as

$$
\Omega>0
$$

The optimal effort level chosen by the inventor is given by

$$
e_{S}^{U S *}=\arg \max _{e_{S}^{U S}}\left(\ln \left(s^{U S}+\sigma\left[B\left(e_{S}^{U S}\right)^{\lambda} q_{S} \pi-c\right]+(\alpha-\sigma) r_{S}^{U S} B\left(e_{S}^{U S}\right)^{\lambda} q_{S} \pi\right)+A \ln \left(T-\gamma e_{S}^{U S}\right)\right)
$$

where $\sigma \in[0,1]$ is the share of startup profits that remain after any equity taken by investors, since she may need to get external financing, in return for which she gives up a share of her firm.. We allow for the case when the startup does not need any external financing: $\sigma=1$. As seen from this expression, the inventor gets income both as a share of profits in the startup, and a share of the royalty that the startup pays to the university . 


\subsection{The Swedish System}

By contrast, in the Swedish system the professor owns her invention and hence chooses the licensee. If she licenses to an established firm she bears a search cost and her licensing income comes from a royalty on net sales, which we assume is exogenous (as we did in the US TTO case). If she chooses to do a startup, there is no search cost, but she may need to get external financing, in return for which she gives up a share of her firm.

If she starts her own firm, her utility is given by

$$
U_{S}^{S W E}=\ln \left(s^{S W E}+\sigma\left(B\left(e_{S}^{S W E}\right)^{\lambda} q_{S} \pi-c\right)\right)+A \ln \left(T-\gamma e_{S}^{S W E}\right)
$$

where $s^{S W E}$ is her university salary in Sweden, $\sigma$ is the share of startup profits that remain after any equity taken by investors, and $e_{S}^{S W E}$ is her optimal effort in the startup under the Swedish system. If she licenses to an established firm, her utility is given by

$$
U_{F}^{S W E}=\ln \left(s^{S W E}+r_{F}^{S W E}\left(B\left(e_{F}^{S W E}\right)^{\lambda} q_{F} \pi\right)-k\right)+A \ln \left(T-\gamma e_{F}^{S W E}\right)
$$

where $e_{F}^{S W E}$ is her optimal effort for the firm and $k$ is her search cost.

The inventor chooses to do a startup if

$$
U_{S}^{S W E}>U_{F}^{S W E}
$$

or defining $\Psi$ as

$$
\Psi=U_{S}^{S W E}-U_{F}^{S W E}
$$

the condition can be stated as

$$
\Psi>0
$$

\section{Baseline model}

To illustrate the differences across the systems, we create a baseline version of the model. In this baseline model, the outcomes are identical under US system and the Swedish system, both in terms of mode of commercialization and the probability that the invention is commercialized.

In the baseline model, we introduce a number of assumptions: first, the inventor has no disutility from development effort. Hence, the effort choice is exogenous and the inventor always provides maximal effort in development. Second, the TTO does not maximize revenue, but instead inventor income. This implies that the objective functions contain the same components for the TTO under the US system and the inventor under the Swedish system. Third, the inventor's share of royalty revenues in the US system, $\alpha$, is equal to 1 , and the royalty rate charged to the startup under the US system, $r_{S}^{U S}$, is equal to zero. Fourth, there are no search costs for finding an established firm; $k=0$. In addition, we impose that the 
environments are identical; university salaries are equal, $s^{U S}=s^{S W E}=s$, and the royalty rates charged to the firms are equal, $r_{F}^{S W E}=r_{F}^{U S}=r_{F}$. Given these assumptions, the TTOs choice of commercialization mode can be restated as follows:

$$
\Omega=s+\sigma\left(B q_{S} \pi-c\right)-\left(s+r_{F} B q_{F} \pi\right)
$$

Hence, the TTO chooses to license to the startup if

$$
\Omega>0
$$

Similarly, the inventor's choice of commercialization mode can be restated as follows:

$$
\Psi=s+\sigma\left(B q_{S} \pi-c\right)-\left(s+r_{F}\left(B q_{F} \pi\right)\right)
$$

The inventor chooses to do a startup if

$$
\Psi>0
$$

and the conditions $\Omega$ and $\Psi$ are identical and can be written as:

$$
\Omega=\Psi=\sigma\left(B q_{S} \pi-c\right)-r_{F} B q_{F} \pi
$$

Comparative statics give $\frac{\partial \Omega}{\partial \sigma}>0, \frac{\partial \Omega}{\partial r_{F}}<0, \frac{\partial \Omega}{\partial q_{S}}>0, \frac{\partial \Omega}{\partial c}<0$ and $\frac{\partial \Omega}{\partial q_{F}}<0$. An increase in $\sigma$ or $q_{S}$, or a decrease in $c$ makes it more likely that the inventor and the TTO will choose to license to a startup. A higher ownership share for the inventor in the startup, $\sigma$, increases her returns to effort since she obtains a larger share of profits. Higher commercialization skills in the startup, $q_{S}$, increases expected income from the startup relative to income from the established firm. As for the development cost, $c$, it is only borne by the inventor if she chooses a startup since the royalty charged to the established firm is based on net sales. Therefore, a decrease in $c$ increases expected income from the startup relative to income from the established firm. An increase in $r_{F}$ or $q_{F}$ makes it more likely that the inventor and the TTO will choose to license to an established firm. A higher royalty rate, $r_{F}$, or higher commercialization skills in the established firm,$q_{F}$, increases expected income from the established firm relative to the startup.

\subsection{Parameterization}

It is clear that the optimal choice of commercialization mode depends on a large number of parameters, even in this baseline model. As seen from $\Omega$, the parameters $\sigma$ and $r_{F}$ are key determinants of the choice, since they govern the share of startup profits and net sales, respectively, accruing to the decision maker. Starting with the inventor's ownership share in the startup, we posit that the inventor can keep at least 10 percent ownership in her startup and allow for the case when she does not need any external financing at all. Hence, $0.1 \leq \sigma \leq 1$ and we divide this interval into ten values; $\sigma \in[0.1,0.2,0.3,0.4,0.5,0.6,0.7,0.8,0.9,1]$. As for the royalty rate charged to the established firm, we allow rates between 0.02 and 0.2 given the wide 
variation in actual rates across industries (Parr 2007). ${ }^{1}$ Hence, $0.02 \leq r_{F} \leq 0.2$ and we also divide this interval into ten values; $r_{F} \in[0.02,0.04,0.06,0.08,0.10,0.12,0.14,0.16,0.18,0.20]$. Consequently, we solve the model for 100 combinations of $\sigma$ and $r_{F}$.

As for the commercialization skills, they are formulated as probabilities of commercialization success, and hence $q_{S} \in(0,1)$ and $q_{F} \in(0,1)$. For simplicity, we set $B=1$, and $\pi$ is normalized to 100 . As for the development cost $c$ it naturally varies across inventions, but our model is too stylized to allow us to infer its value from data. We choose the following approach. Guided by the comparative statics results, we generate three cases, which are representative of the optimal choices of mode over the entire parameter space.

The first case is where the established firm has no advantage in commercialization, and the fixed development cost is very low. We denote this the equal commercialization skills case, and parameterize it as $q_{S}=q_{F}=0.1, c=0.1$. This is the case that is most conducive to choosing the startup, as shown by $\frac{\partial \Omega}{\partial c}<0$ and $\frac{\partial \Omega}{\partial q_{F}}<0$. The second case is where the established firm has an advantage in commercialization but the development cost is still very low. We denote this the firm skill advantage case, and parameterize it as $q_{S}=0.1, q_{F}=0.25, c=0.1$. This case is less conducive to choosing the startup. The third case is where the established firm has a larger advantage in commercialization and the development cost is high. We denote this the firm general advantage case, and parameterize it as $q_{S}=0.1, q_{F}=0.9, c=5$. This is naturally the case that is least conducive to choosing the startup. Hence, with these three cases we can capture the optimal commercialization mode in situations that are most conducive to startups and firms respectively, as well as an intermediate situation.

Within each of the three cases, we vary the key parameters $\sigma$ and $r_{F}$ over ranges described above and using the expression for $\Omega$ we can determine the optimal commercialization mode from point of view of the TTO and the inventor alike.

The numerical solution to the baseline model yields the following results, presented in Table 1. Starting with the equal commercialization skills case, the TTO and the inventor choose to license the invention to the startup in 93 percent of the combinations of $\sigma$ and $r_{F}$. As stated above, this is the case that is most conducive to choosing the startup.

\footnotetext{
${ }^{1}$ For royalty rates in biotechnology, rates are quite low. For example, Edwards et al. (2003) report effective rates of .04, and Higgins et al. (2011) report .02. The higher rates in this range reflect licenses for products closer to commercialization than the typical biotech invention.
} 
Table 1: Percent of cases where invention is licensed to startup

\begin{tabular}{llll} 
& Baseline & \multicolumn{2}{c}{ Two systems } \\
& & US & Swe \\
equal skills & 93 & 100 & 93 \\
firm skill advantage & 75 & 8 & 75 \\
firm general advantage & 10 & 0 & 7 \\
\hline
\end{tabular}

The few cases where the agents choose to license to the established firm is, as indicated by the comparative statics $\frac{\partial \Omega}{\partial \sigma}>0$ and $\frac{\partial \Omega}{\partial r_{F}}<0$, when $\sigma$ is low and $r_{F}$ is high. In the firm skill advantage case, the higher commercialization skills possessed by the firm implies that for given values of $\sigma$ and $r_{F}$, the agents are more likely to choose to license to the established firm, and hence the cutoff points for $\sigma$ for which the agents choose the startup shifts up, and the cutoff point for $r_{F}$ for which the agents choose the startup shifts down. Now, the TTO and the inventor choose to license the invention to the startup in 75 percent of the combinations of $\sigma$ and $r_{F}$. In the firm general advantage case, the additional incentive for licensing to an established firm that lies in a higher development cost and in higher commercialization skills implies that the TTO and the inventor chooses the startup in only 10 percent of the combinations or $\sigma$ and $r_{F}$; that is when $\sigma$ is high and $r_{F}$ is low.

\section{Two Systems Compared}

Now, we relax the most restrictive assumptions from the baseline model, and thereby allow for the two different institutional regimes in Sweden and the US. We choose the following parameterization. The parameter $\alpha$, the inventor's share of license revenues under the US system, is set to 0.4 , which corresponds to the average share among US universities. We assume that the TTO cannot discriminate between licensees, and therefore the royalty rate charged to the startup is equal to the royalty rate charged to the established firm: $r_{S}=r_{F}$. For lack of empirical estimates, the parameter $\lambda$, which governs the concavity of the development success function, is set to an intermediate value: 0.5. A robustness analysis with respect to $\lambda$ is presented in Section 7. The weight on research in the inventor's utility function, $A$, is set to 0.3 . In Section 7 , we also analyze how an increase in $A$ affect the results. The inventor's university salary in both Sweden and the US is normalized to 1. Similarly, the total time available for the inventor is normalized to 1 . In this analysis, we exclude any search costs in finding a licensee. Hence, we set $k=0$. In Section 8, we will introduce a search cost and conduct policy experiments with respect to the cost. 


\subsection{Numerical results}

As before, we solve the model for the three cases: equal commercialization skills case, firm skill advantage case and the firm general advantage case. We start with the results for the US system and then turn to the results for the Swedish system. As seen in Table 1, in the US system, we find that in the equal commercialization skills case, the TTO chooses the startup in 100 percent of the combinations of $\sigma$ and $r_{F}$. In the firm skill advantage case, the corresponding number is 8 percent, and in the firm general advantage case it is 0 percent. Compared to the baseline model, we note that when the TTO maximizes license revenue instead of inventor utility, the inventor's ownership share and the royalty rate charged to the firm are less important for the choice of commercialization mode. In the former case, the ownership share now enters into the TTOs optimization only indirectly, through the inventor's effort level. In the latter case, the royalty rate charged is now identical across mode, and therefore has a lower impact. As seen from the expression for $\Omega$ :

$$
\Omega=(1-\alpha) r_{S}\left(B\left(e_{S}^{U S *}\right)^{\lambda} q_{S} \pi\right)-(1-\alpha) r_{F}\left(B\left(e_{F}^{U S *}\right)^{\lambda} q_{F} \pi\right)
$$

in the equal commercialization skills case where $q_{S}=q_{F}$, the TTO's decision is completely determined by the optimal effort levels $e_{S}^{U S *}$ and $e_{F}^{U S *}$. From the inventor's utility function, we see that given $r_{F}=r_{S}$ and $q_{F}=q_{S}$ the inventor has a higher income for a given effort level if she chooses startup as long as $\sigma>0$. Therefore, the inventor exerts more effort in the startup for all $\sigma \in[0.1,1]$ and $r_{F} \in[0.02,0.2]$. Essentially, since the TTO charges both startup and firm the same royalty rate, the inventor gets a share $\alpha$ of that royalty in both cases. In the startup, however, she gets a share $\sigma$ of the firm profits net of royalty payments in addition to that, which increases her effort, and $e_{S}^{U S *}>e_{F}^{U S *}$.

When we turn to the firm skill advantage case the picture is different. The inventor still exerts more effort in the startup, but the TTO now faces a trade-off between choosing the firm, which has higher commercialization skills, and choosing the startup, for which the development effort is higher. Now, the percentage of startups chosen decreases from 75 percent to 8 percent, and one factor contributing to that result is the decreasing returns to development effort, which implies that the TTO puts more weight on the commercialization skills. This result can be compared to data on US university licensing; Jensen and Showalter (2011) report that startup licenses represent little more than $10 \%$ of licenses executed. In the firm general advantage case, the higher level of development costs only enters into the TTO's decision problem indirectly, through the inventor's effort level. It increases $e_{S}^{U S *}$, but the inventor's higher effort level is never sufficiently high to outweigh the difference in commercialization skills.

Under the Swedish system, the results show that in the equal commercialization skills case, the inventor chooses the startup in 93 percent of the combinations of $\sigma$ and $r_{F}$. The corresponding number for the firm skill advantage case is 75 percent, and finally, in the firm general advantage case it is 7 percent. Compared to the baseline model, we see that when the effort level is made endogenous, it has a minor impact on the inventor's choice of mode. In contrast to the US system, the optimal effort is chosen to maximize the 
same objective function, namely the inventor's utility function, as the choice of commercialization mode. One reason why the inventor prefers the startup to a greater extent than the TTO is that even if the established firm has an advantage, the inventor can, in many instances, collect a larger share of profits from commercialization when she chooses the startup than when she licenses to the established firm. In the first case, the inventor owns between 10 and 100 percent of the firm, and of its profits, whereas in the latter case, the inventor gets a royalty rate between 2 and 20 percent of revenues.

Table 2 displays the average effort levels provided by the inventor in the US and Sweden respectively, for the three cases. As argued above, one main difference between the two systems is that the US system can create an agency problem, whereas the Swedish does not. In the table, if we compare the average effort provided by the inventor in the firm for the equal commercialization skills case, it is significantly higher in Sweden than in the US; 0.37 compared to 0.21. This difference is due to the agency problem. The inventor only captures a share of the expected income, and therefore provides less effort. For the same reason, the effort levels in the established firm are higher in Sweden than in the US for the firm skill advantage case and the firm general advantage case. However, if we turn to the startup and compare the effort provided in the equal commercialization skills case, we see that the average effort levels are not very different across countries. If the inventor works for a startup, the agency problem built into the US system has a small impact on effort on average. The reason is that even though the inventor's firm has to pay a royalty to the university under the US system, the inventor gets a share of that royalty, and if her ownership share is low in relation to her share of royalty revenues, the royalty payment can even generate a net increase in income. Therefore, the average effort levels over the combinations of $\sigma$ and $r_{F}$ are similar.

Table 2: Average inventor effort levels

\begin{tabular}{llllll}
\hline \multicolumn{5}{c}{ Two systems } \\
& US & \multicolumn{3}{l}{ Swe } \\
& $\mathrm{S}$ & $\mathrm{F}$ & $\mathrm{S}$ & $\mathrm{F}$ \\
equal skills & 0.562 & 0.207 & 0.557 & 0.367 \\
firm skill advantage & 0.562 & 0.367 & 0.557 & 0.493 \\
firm general advantage & 0.708 & 0.529 & 0.723 & 0.586 \\
where S=startup and F=established firm & & \\
\hline
\end{tabular}

In addition, the table conveys that effort levels are generally much higher in the startup than in an established firm. In the equal commercialization skills case, the average development effort in the startup is more than double that in the established firm in the US system. In the Swedish system, the difference is smaller. The main explanation for this difference is that the upper bound on the royalty rate charged 
to the firm is 0.2 whereas the ownership share has an upper bound of 1 . This explains the difference in efforts in the Swedish system. However, in the US, there is an additional effect, as mentioned above. Since the TTO charges the same royalty rate from both startup and firm, the inventor gets a higher income from the startup since she has some positive ownership share.

From Table 2, we also see that inventor effort is generally higher in the firm general advantage case than in the firm skill advantage case. When the inventor works for the firm, the increase in firm commercialization skills naturally increases her incentives to provide effort. However, we see than average effort increases also when the inventor works for the startup. The explanation is that inventor effort is increasing in the development cost, $c$. The development cost is fixed, paid up-front, and it reduces inventor income. Since the inventor's utility function exhibits decreasing marginal utility, a higher development cost implies that the inventor has a higher marginal utility of income, and since higher effort results in higher expected income, the inventor chooses a higher effort level.

It is clear that the two institutional regimes affect commercialization mode. The next step is to analyze the differences in probability of successful commercialization. We start with the equal commercialization skills. In this case, differences in probability of successful commercialization depend entirely upon differences in inventor effort. Table 3 shows that on average, the probability of successful commercialization is slightly higher in the US than in Sweden, but the magnitude is such that it may not be of any economic importance. However, the averages conceal interesting differences depending on the values of $\sigma$ and $r_{F}$. It is more likely that the invention is commercialized in the US if $\sigma$ is low and $r_{F}$ is low, and conversely in Sweden if $\sigma$ is high and $r_{F}$ is high. When modes are identical, the inventor works for a startup in both countries, but in Sweden she increases effort more in response to an increase in ownership share. It is only in the US system that the startup pays a royalty rate $r_{F}$, and hence an increase in that rate reduces inventor effort in the US but not in Sweden.

Table 3: Average probability of commercialization success

\begin{tabular}{lll}
\hline & \multicolumn{2}{l}{ Two systems } \\
& US & Swe \\
equal skills & 0.0749 & 0.0747 \\
firm skill advantage & 0.1484 & 0.1031 \\
firm general advantage & 0.6523 & 0.6503 \\
\hline
\end{tabular}

In the firm skill advantage case, the average probability of successful commercialization is higher in the US than in Sweden. The TTO is more likely than the inventor to choose the established firm, which for a given development effort level results in a higher probability of commercialization success. When taking effort levels into account, the former effect dominates, and the probability of commercialization 
success is higher in the US than in Sweden if the TTO has chosen the established firm and the inventor has chosen the startup. However, when both TTO and inventor choose to license to the established firm, which occurs for high values of $r_{F}$, success is higher in Sweden, due to higher inventor effort. This is a direct result of the agency problem; in the US, the inventor only captures a share $\alpha<1$ of license revenue from the established firm, whereas in Sweden the inventor gets total license revenue.

In the firm general advantage case, the average probability of commercialization success is slightly higher in the US than in Sweden. The differences in averages is very small, but commercialization success is much higher in the US for low values of $r_{F}$, which is when the TTO chooses the firm but the inventor chooses the startup. In the startup, the inventor exerts more effort, but the established firm's substantial skill advantage in commercialization implies a much lower probability of commercialization success when the startup develops the invention. When both agents choose the established firm, the probability of commercialization success is higher in Sweden since the agency problem implies a lower effort level for the inventor. In general, across cases, the average probability of commercialization success is higher in the US that in Sweden (although sometimes only slightly higher).

\section{Robustness analysis}

To assess the sensitivity of our numerical results to the chosen parameter values, we now perform a robustness analysis with respect to the three main parameters that have hitherto been held fixed; $A, B$ and $\lambda$.

We start with varying $A$, the relative weight on the income and basic research parts of utility. We increase $A$ from 0.3 to 1 , to explore the case when the inventor prefers to do basic research. As a result, the inventor exerts less effort in development, both in the startup and in the established firm. This occurs under both the Swedish and the US system, as seen when comparing Table 4 to Table 2. However, since the probability function for development is concave in effort, the reduction in effort induces a larger reduction in probability of success in development for low initial levels of effort. The average effort level is lower in the firm than in the startup, implying that licensing to the firm now becomes relatively less attractive. In addition, the inventor suffers a higher reduction in utility, for a given level of effort. 
Table 4: Robustness checks, average inventor effort levels

\begin{tabular}{|c|c|c|c|c|c|c|c|c|c|c|c|c|}
\hline & \multicolumn{4}{|c|}{$A=1$} & \multicolumn{4}{|c|}{$B=1.2$} & \multicolumn{4}{|c|}{$\lambda=0.9$} \\
\hline & US & & Swe & & US & & Swe & & US & & Swe & \\
\hline & S & F & S & $\mathrm{F}$ & S & $\mathrm{F}$ & S & $\mathrm{F}$ & S & $\mathrm{F}$ & S & F \\
\hline equal skills & 0.26 & 0.04 & 0.25 & 0.11 & 0.57 & 0.24 & 0.57 & 0.40 & 0.70 & 0.23 & 0.69 & 0.46 \\
\hline firm skill adv. & 0.26 & 0.11 & 0.25 & 0.20 & 0.57 & 0.40 & 0.57 & 0.51 & 0.70 & 0.46 & 0.69 & 0.62 \\
\hline $\begin{array}{l}\text { firm general adv. } \\
\text { where } \mathrm{S}=\text { startup }\end{array}$ & 0.33 & 0.23 & 0.31 & 0.28 & 0.69 & 0.54 & 0.69 & 0.59 & 0.79 & 0.66 & 0.74 & 0.72 \\
\hline
\end{tabular}

This latter effect is taken into account by the inventor in her choice of commercialization mode, but not by the TTO. Hence, under the US system, the inventor's preference for basic research makes the TTO more prone to license to a startup. The results on commercialization mode are presented in Table 5 below. Comparing Table 5 to Table 1, it is clear that in the equal skills case, that has no effect on commercialization modes as the TTO already chooses the startup in 100 percent of the cases. In the firm skill advantage case, the TTO now chooses to license to the startup more frequently. In the firm general advantage case, the reduction in development effort cannot outweigh the advantages conferred to the established firm.

Table 5: Robustness checks, percent of cases invention is licensed to startup

\begin{tabular}{lllllll}
\hline & $A=1$ & \multicolumn{2}{c}{$B=1.2$} & \multicolumn{2}{c}{$\lambda=0.9$} \\
& US & Swe & US & Swe & US & Swe \\
equal skills & 100 & 93 & 100 & 93 & 100 & 93 \\
firm skill adv. & 18 & 75 & 0 & 75 & 19 & 75 \\
firm general advantage & 0 & 2 & 0 & 10 & 0 & 6 \\
\hline
\end{tabular}

Under the Swedish system, the inventor's preference for basic research has two opposing effects on her choice of commercialization mode. In the equal skills case and the firm skill advantage case, the two effects balance and there is no effect on the inventor's choice of mode. However, in the firm general advantage case, the reduction in utility from doing development effort outweighs the reduction in effort levels, so that the inventor licenses more often to the established firm, where she exerts less effort.

Comparing the average probability of commercialization success across the two systems, we see in Table 6 that when the inventor prefers basic research, the average probability of commercialization success can be higher in Sweden than in the US. This occurs in the firm general advantage case, and is a result of the fact that inventor development effort in the established firm is greater in Sweden than in the US. 
Table 6: Robustness checks, average probability of commercialization success

\begin{tabular}{lllllll}
\hline & \multicolumn{2}{c}{$A=1$} & \multicolumn{2}{c}{$B=1.2$} & \multicolumn{2}{c}{$\lambda=0.9$} \\
& US & Swe & US & Swe & US & Swe \\
equal skills & 0.0504 & 0.0502 & 0.0907 & 0.0906 & 0.0721 & 0.0720 \\
firm skill adv. & 0.0828 & 0.0696 & 0.185 & 0.125 & 0.131 & 0.0995 \\
firm general adv. & 0.424 & 0.472 & 0.794 & 0.763 & 0.620 & 0.637 \\
\hline
\end{tabular}

Next we vary the parameter $B$, which affects the productivity of effort in the probability of development success. We increase $B$ from 1 to 1.2, to reflect a situation where the inventor's effort has a high impact on the probability of success in development. An increase in $B$ affects both optimal effort and the probability of success for a given effort level, something that the TTO and the inventor take both into account. As seen in Table 4 when compared to Table 2, a higher $B$ increases the inventor's effort in both the startup and the firm, except in the firm general advantage case, where effort in the startup decreases for high levels of $\sigma$. The reason is that the startup faces very high development costs, a share $\sigma$ of which are borne by the inventor. This implies that the optimal effort level is very high, and an increase in $B$ allows the inventor to decrease effort and still obtain a high probability of success.

The increase in $B$ affects the TTO's optimal mode of commercialization as follows. In the firm skill advantage case, the TTO decreases its licensing to the startup, as shown in Table 5 compared to the corresponding number in Table 1. The intuition is that the average optimal effort level in the startup increases less than the average optimal effort level in the established firm. This is due to the fact that if the inventor owns a large share of her startup, the royalty payments she must pay to the university decrease her return from increasing effort. The increase in $B$ also affects the inventor's optimal mode of commercialization, but the result is a small decrease in the licensing to the established firm, and the mechanism is different. The decrease occurs in the firm general advantage case, and it occurs because the increase in $B$ allows the inventor to decrease optimal effort, which increases her utility.

The effect of an increase in $B$ on the average probability of commercialization success can be seen when comparing Table 6 to Table 3 . There is a general increase due to the increase in development effort. Comparing the US and Swedish systems, the rate is higher in the US for all cases.

Lastly, we vary the parameter $\lambda$, which governs the concavity of the development success function. We increase $\lambda$ from 0.5 to 0.9 to explore a scenario where there are close to constant returns to scale in development effort. This change increases optimal effort levels in general, as seen from comparing Table 4 and Table 2. In addition, a comparison of commercialization modes in Tables 5 and 1 shows that a higher value of $\lambda$ implies that in the firm skill advantage case, the TTO chooses to license to the startup more often. the reason is that the average increase in effort is higher in the startup than in the firm. The inventor, on the other hand, chooses the startup slightly less often, and it occurs in the firm general advantage case. In this case, effort in the startup is already at such a high level before the increase in $\lambda$ 
that inventor effort in the established firm increases more. In addition, the inventor takes into account the large decrease in utility that results from increasing effort in the startup from an already high level.

Lastly, Table 6 displays the effect of close to constant returns to scale in development effort on average probability of commercialization success. It shows that, as in the case when the inventor prefers basic research, the average probability of commercialization success can be higher in Sweden than in the US. This occurs in the firm general advantage case, and is a result of the fact that inventor development effort in the established firm is greater in Sweden than in the US.

To sum up, the robustness checks show that the main results for the US system are robust to changes in the inventor's preference for basic research, the productivity of the development effort or the degree of decreasing returns to development effort when firms have equal skills or when the established firm has a general advantage. However, when the established firm has a skill advantage, these changes affect the mode of licensing. If the inventor prefers basic research or if there are close to constant returns to scale in development effort, the TTO chooses to license to startups more often, and if development effort is very productive, the TTO chooses to license to startups less often. Similarly, the main results for the Swedish system are robust when firms have equal skills or when the established firm has a skill advantage. When the established firm has a general advantage, these changes affect the mode of licensing. If the inventor prefers basic research or if there are close to constant returns to scale in development effort, the inventor chooses the startup less often and if development effort is very productive, the inventor chooses the startup more often. Nevertheless, the Swedish system is still more conducive to startups if established firms have some kind of advantage.

The changes in commercialization mode also affect average probabilities of commercialization success. The result that the average probability of commercialization success is always higher in the US, is robust to changes in productivity of the development effort. However, if the inventor prefers basic research or if there are close to constant returns to scale in development effort and any of the two is combined with a general advantage for the established firm, then indeed the average probability of commercialization success is higher in Sweden. From this analysis, it is clear that which country has the highest probability of commercialization success depends crucially on which commercialization mode the TTO and the inventor choose. When both agents choose to license to an established firm, the agency problem present in the US implies that the inventor exerts more effort in Sweden, and the latter has a higher rate of commercialization success. When the TTO chooses to license to an established firm while the inventor chooses the startup, which system generates the highest probability of commercialization success hinges on whether the established firm has an advantage in commercialization or not. When both the TTO and the inventor chooses to license to the startup, it is more likely that the invention is commercialized in the US if $\sigma$ is low and $r_{F}$ is low, and conversely in Sweden if $\sigma$ is high and $r_{F}$ is high.

A higher probability of commercialization success in the US is generally a result of the fact that the TTO chooses to license to an established firm which has an advantage in commercialization skills, whereas 
the inventor prefers the startup. In the instances where the probability of successful commercialization is higher in Sweden, it is due to the fact that when both agents choose to license to an established firm, the agency problem present in the US implies that the inventor exerts less effort.

Lastly, it is important to bear in mind that the results in the main model as well as the robustness analysis rest on the premise that the ten values for the ownership share in the startup, $\sigma$, and the royalty rate charged to the established firm, $r_{F}$, in the chosen intervals are equally likely to occur.

\section{Policy experiments}

In this section, we use our model to perform four policy experiments, based on policies that have been suggested by the policy debates discussed earlier. First, we introduce a cost to searching for an established firm into the model. The difference between the two systems in this case is that in the US, the TTO bears the cost while in Sweden the inventor bears this cost. This will allow us, not only to examine differences in the burden on the TTO and the faculty member, but also allows us to examine the impact of the type of internet based mechanisms suggested earlier (Litan et al. 2008). Notice that, while the internet alternative was raised in the US context, such systems could expedite commercialization under both systems. Thus in first policy experiment, we consider a reduction in search costs under both the Swedish and US systems.

The second, third and fourth experiments are conducted only for the US system. The second responds directly to Recommendation 10 by the NAS study; to promote entrepreneurial ventures. The third analyzes the case when the TTO has an advantage, generated for example by economies of scale, in finding an existing licensee. The fourth responds to empirical evidence in the US that in many cases the faculty are better positioned than the TTO to find an existing licensee (Thursby and Thursby 2000).

\subsection{Search costs}

First, we introduce costs in searching for established firms as potential licensees. Licensing to the inventor startup involves no search. The search cost is borne by the inventor in the Swedish system, and by the TTO in the US system. It is possible that the two agents face costs of different magnitudes, and we will allow for that possibility later. Initially, we will assume that both TTO and inventor incur the same search cost, and parameterize our model as follows: the search cost for finding an established firm to license the invention to is $k=0.9$. The share of that cost that the TTO incurs, $v$, is equal to 1 .

Introducing a search cost has the following effects in this model. In the US system, the search cost decreases net income from licensing to an established firm relative to licensing to a startup. However, it does not affect inventor effort in the established firm, since the inventor does not bear the cost. In the Swedish system, the search cost decreases inventor income from licensing to an established firm, and it 
also affects inventor effort directly. The search cost is a fixed cost, and it reduces the inventor's total income. Since the inventor's utility function is concave in income, a lower income level implies a higher marginal utility from income and consequently, the inventor exerts more effort in development.

The numerical solutions show that introducing search costs has a large effect on commercialization mode in both the US and Sweden. Comparing Table 7 to Table 1, the percent of cases where the invention is licensed to a startup increases from 8 percent to 70 percent in the US and from 75 to 88 percent in Sweden, in the firm skill advantage case. Similarly, in the firm general advantage case, the percent of cases where the invention is licensed to a startup increases from 0 percent to 10 percent in the US and from 7 to 13 percent in Sweden. The increase is larger in the US than in Sweden, since in the Swedish system, the increase in the inventor's effort level mitigates the direct effect of the cost.

Table 7: Percent of cases where invention is licensed to startup

\begin{tabular}{llllllll}
\hline & Search costs & \multicolumn{2}{l}{ Internet based } & C-license & TTO & TTO \\
& & \multicolumn{2}{l}{ system } & & advantage & disadvantage \\
& \multicolumn{2}{l}{$k=0.9, v=1$} & $k=0.6, v=1$ & $k=0.9, v=1$ & $k=0.9, v=0.5$ & $k=0.9, v=1.2$ \\
& US & Swe & US & Swe & US & US & US \\
equal skills & 100 & 100 & 100 & 99 & 100 & 100 & 100 \\
firm skill adv. & 70 & 88 & 50 & 84 & 59 & 40 & 87 \\
firm general adv. & 10 & 13 & 10 & 11 & 9 & 0 & 10 \\
\hline
\end{tabular}

If we turn to the effect of search costs on the average probability of commercialization success, Table 8 reveals that commercialization success weakly decreases in both the US and Sweden for all cases as compared to Table 3. Generally, when both the TTO and the inventor choose the startup to a greater extent, commercialization success decreases if the established firm has an advantage in commercialization.

In addition, with search costs the choices of commercialization mode made by the TTO and the inventor are more aligned. Both the inventor and the TTO choose to license to the startup for low values of $r_{F}$. Now, the effort levels across Sweden and the US are almost identical, and hence the differences in the probability of commercialization success decrease. However, it is still the case that when both agents choose the established firm, the probability of commercialization success is higher in Sweden than in the US, and this effect generates a higher average probability of commercialization success in the firm general advantage case . 
Table 8: Average probability of commercialization success

\begin{tabular}{lllllllll}
\hline & \multicolumn{2}{l}{ Search costs } & \multicolumn{2}{l}{ Internet based } & C-license & TTO & TTO \\
& \multicolumn{7}{c}{$\begin{array}{l}\text { system } \\
\text { advantage }\end{array}$} & disadvantage \\
& US & Swe & US & Swe & US & US & US \\
equal skills & 0.0749 & 0.0745 & 0.0749 & 0.0746 & 0.0720 & 0.0749 & 0.0749 \\
firm skill adv. & 0.105 & 0.0901 & 0.123 & 0.0945 & 0.113 & 0.131 & 0.0881 \\
firm general adv. & 0.609 & 0.632 & 0.609 & 0.639 & 0.613 & 0.652 & 0.609 \\
\hline
\end{tabular}

\subsection{Internet based system}

With an internet-based system for finding potential licensees among established firms, the search costs go down both for the TTO in the US system and for the inventor in the Swedish system. We model the introduction of these systems as a reduction in $k$. The effect on commercialization mode is displayed in Table 7. As seen from the table, in the equal commercialization skills case, there is virtually no effect. The decrease in cost is not sufficiently large to induce neither TTO nor inventor to switch from licensing to the startup in more than one instance. In the firm skill advantage case, there is a large shift to established firms by the TTO, and a smaller shift by the inventor. The reason is that the search cost $k$ reduces the TTOs license revenue directly but does not affect inventor effort, while in the Swedish system it reduces income, but also increases inventor effort because of the higher level of marginal utility of income. In the firm general advantage case, the decrease in search cost has no effect on commercialization mode in the US, and only a very small effect in Sweden.

If we turn to differences in the average probability of commercialization success, we see from Table 8 that in the equal commercialization skills case there is virtually no effect of the decrease in $k$, which is natural given that there was a very small change in commercialization mode. In the firm skill advantage case, commercialization success is higher. This is a result of the fact that the established firm is chosen more often, and it has an advantage in commercialization. The same holds for the increase in commercialization success in Sweden in the firm general advantage case.

Hence, an internet based system for finding licensees induces both the TTO and the inventor to choose to license to an established firm to a greater extent. When established firms have an advantage in commercialization, that also results in higher probabilities of commercialization success. The largest effect is obtained in the US case, when firms have a skill advantage but not a general advantage, which is when the reduction in cost can induce the largest differences in commercialization mode.

\subsection{Carnegie license}

In the US, universities have moved toward adopting license templates designed to expedite startup formation. This type of license responds to the National Academies' recommendation that university TTOs 
make greater efforts to facilitate faculty entrepreneurship. One of the first universities to adopt such a format was Carnegie Mellon University. As is common in such formats, the faculty member agrees to forego her share of license revenue, and royalty fees are not charged for a number of years. In lieu of this, the university takes a fixed ownership share, which in the Carnegie case is 6 percent of the startup. Hence, the inventor receives no royalty revenues. This license template is not used for licensing to an established firm. In our model, we postulate that the fixed ownership share reduces the inventor's ownership share by the same amount, so that the share held by outside parties is constant.

Using a Carnegie license affects the inventor's effort level in the startup, as she gets a lower share of equity and no license revenue. Hence, she exerts less effort in all cases, except when $\sigma$ is close to 1 and $r_{F}$ is very high. When the TTO goes from charging a royalty to taking an ownership share in the startup, it has the following effects on the choice of commercialization mode. As seen in Table 7, the TTO chooses to license to the startup less often, compared to the case with search costs, except in the equal skills case, where it has no effect. The intuition for this result is that now, the TTO only gets 6 percent of profits from the startup whereas it can get up to 60 percent of a royalty of 20 percent of net sales if it licenses to an established firm. In addition, the inventor exerts less effort in the startup.

As regards the effects of the Carnegie license on the probability of commercialization success, Table 8 reveals that in the equal commercialization skills case, there is a decrease in commercialization success. It stems from the fact that the inventor reduces her development effort in the startup. On the contrary, in the firm skill advantage case commercialization success increases. Now, the TTO chooses the established firm more often, and it has an advantage in commercialization. In the firm general advantage case, there is a decrease in commercialization success. The negative effect of lower inventor effort in the startup outweighs the positive effect of choosing the established firm more often.

Introducing a Carnegie license implies that the inventor exerts less development effort in the startup, and that the TTO chooses to license to the established firm more often. Whether that results in a higher or lower probability of commercialization success depends on whether the established firm has an advantage in commercialization or not.

\subsection{TTO advantage or disadvantage}

Now, we want to analyze the effects if the TTO has an advantage over the inventor in searching for established firms as licensees. The advantage can be due to increasing returns to finding licensees, or to skill differences. We model this difference as a decrease in $v$ from 1 to 0.5 , while the cost $k$ is kept constant. We solve the model for the US and compare to the outcome in Sweden when there are search costs. The decrease in $v$ has no effect on inventor effort in the US, as it is the TTO that bears the cost. The differences in commercialization mode are shown in Table 7. As seen from the table, the TTO chooses the startup less often than the inventor in Sweden, except in the equal commercialization skills case. The 
result is straightforward, since the relative cost of licensing to an established firm is low and the expected revenues are constant. In fact, in the firm general advantage case, the TTO never chooses the startup, whereas the inventor in Sweden chooses the startup in 13 percent of the combinations of $\sigma$ and $r_{F}$.

If we turn to the effects of a TTO advantage on commercialization success, Table 8 shows that the average probability of commercialization success is higher in the US than in Sweden in all cases. In the equal skills case, it is, as described earlier, due to the fact that on average, inventor effort is slightly higher in the US than in Sweden. In the firm skill advantage case and firm general advantage case, the higher commercialization probability is explained by the fact that the TTO chooses the established firm more often, and it has higher commercialization skills.

We also analyze the case where the TTO has a disadvantage in searching for established firms as licensees The disadvantage can be due to lack of TTO resources, or due to inventor connections with established firms resulting from sponsored research, consulting or other interactions. We model this difference as an increase in $v$ from 1 to 1.2 , while the cost $k$ is kept constant. We solve the model for the US and compare to the outcome in Sweden when there are search costs. The results on mode of commercialization are presented in Table 7. The table shows that the TTO still chooses the startup less often than the inventor, but the differences are very small. If we turn to Table 8 , the results show that the average probability of commercialization success is higher in the US in the equal skills case, but higher in Sweden for the two remaining cases. The explanation for the latter result is that when both the inventor and the TTO chooses the firm, the agency problem reduces inventor effort in the US relative to Sweden, and the search cost itself increases inventor effort in Sweden whereas it does not affect inventor effort in the US.

Consequently, if the TTO has a disadvantage in searching for established firms, the commercialization modes in Sweden and the US are rather similar. However, the average probability of commercialization success differs, and if the established firm has an advantage, commercialization success is higher in Sweden than in the US.

\section{Concluding Remarks}

A simple reading of SOU 2005:95 and Merrill and Mazza (2011) makes it clear that policy analysis has been hampered by a lack of systematic comparisons of the ownership models behind technology transfer in the two countries. In this paper, we take a step toward framing such a comparison. We construct a simple model which allows us to examine some of the salient differences in the two systems. In particular, we examine the impact of different decision makers on the mode of commercialization, inventor effort under each mode, and the probability of successful commercialization in the two environments. We also examine the effects of several of the policies recently recommended, such as internet based marketing and 
the Carnegie license in the US.

Our results show the systems are, indeed, different and different in more nuanced ways than one might expect. For example, it has been argued in the policy debate that Technology Transfer Offices can have both advantages and disadvantages in identifying licensees relative to faculty inventors. However, our analysis shows that the mere presence of costs of identifying a licensee, identical for both TTO and inventor, introduces a difference between the systems. Since these costs are borne by the TTO in the US, they do not affect inventor effort - further driving a wedge between the decision makers in the US.

Comparing the systems, we find that the US system is less conducive to entrepreneurship than the Swedish system if established firms have some advantage over faculty startups. Further, the average probability of successful commercialization is generally somewhat higher in the US. However, if there are search costs in finding an established firm, if the inventor prefers basic research or if there are close to constant returns to scale in development effort, and any of the three is combined with a general advantage for the established firm, then the average probability of commercialization success is higher in Sweden.

Our policy experiments further highlight the differences in outcomes. For example, the reduction in search costs implied by internet-based marketing makes no difference in the commercialization mode in the US when inventor and firm skills are equal (or when the firm has a general advantage). Only in the intermediate case of a firm skill advantage do we see a substantial change in the US mode of commercialization. In Sweden, however, there is a general increase in licensing to an established firm . The reason is that in Sweden the search costs affect inventor effort as well as mode of commercialization.

The Carnegie license experiment also produces surprising results. The Carnegie license was one of the first examples of the type of expedited policy prescribed in Merrill and Mazza (2011). When the inventor and the established firm have equal skills there is no difference; the TTO in our model always licenses to the startup. However, when the firm has an advantage, the portion of cases where the invention is licensed to a startup goes down. The reason is that under the Carnegie license the TTO takes a cap of $6 \%$ equity in the startup while it can collect higher royalties from the firm.

Finally, our consideration of TTO versus inventor advantages in identifying licensees shows the importance of TTO resources, or the lack thereof, discussed in SOU 2005:95 and other studies (Braunerhjelm 2007). When the TTO has an advantage the likelihood of commercialization is improved. In the opposite case-TTO disadvantage - the likelihood of commercialization is equal or slightly less. Compared to the Swedish system, professor privilege gives a likelihood of commercialization which is higher than that when the TTO has a disadvantage (except when inventor and firm skills are equal ) but is lower than when the TTO has an advantage.

We emphasize that the major takeaway from this exercise is does not lie in the specific results, but in the demonstration that systematic comparisons of the two systems are critical. These results have come from a simple model. For example, we have not compared the outcome of different financing environments in Sweden and the US. While we have modeled the need for inventor effort for embryonic inventions, we 
have not explicitly modeled the fact that in many cases, the ultimate application of inventions is unknown at the time of license. 


\section{References}

[1] Conti, A. (2009), "Managing Innovations Resulting from University-Industry Collaborations", Mimeo.

[2] Braunerhjelm, P. (2007), "Academic Entrepreneurship: Social Norms, University Culture and Policies", Science and Public Policy, 34, 619-631.

[3] Braunerhjelm, P. and R. Svensson (2010), "The Inventor Role: Was Schumpeter Right?", Journal of Evolutionary Economics, 20, 314-44.

[4] Dechenaux, E., M. Thursby and J. Thursby (2011), "Inventor Moral Hazard in Licensing: The Role of Contracts", Research Policy, 40, 94-104.

[5] Di Gregorio, D. and S. Shane (2003), "Why Do Some Universities Generate More Start-ups Than Others?", Research Policy, 32, 209-227

[6] Edwards, M., F. Murray, and R. Yu (2003), "Value Creation and Sharing Among Universities, Biotechnology and Pharma", Nature Biotechnology, 21, 618-624.

[7] Geuna, A., L. J. J. Nesta (2006), "University patenting and its effects on academic research: the emerging European evidence", Research Policy, 35, 790-807

[8] Greenburg, D. (2007), Science for Sale: The Perils, Rewards, and Delusions of Campus Capitalism. The University of Chicago Press: Chicago

[9] Goldfarb, B., and M. Henrekson (2003), "Bottom-up versus top-down Policies Twoards the Commercialization of University Intellectual Property", Research Policy, 32, 639-658.

[10] Henrekson, M. and N. Rosenberg (2001), "Designing Efficient Institutions for Science-Based Entrepreneurship: Lesson from the US and Sweden", Journal of Technology Transfer, 26, 207-231.

[11] Higgins, M., J. Thursby and M. Thursby (2010), "The Nexus of NIH Funding for University Science and Biopharmaceutical Applications", in Why Invest in Biomedical Research, Office of Science Policy Analysis. National Institutes of Health: Bethesda, MD.

[12] Jensen, R., and D. Showalter (2010), "Commercializing University Inventions with Startups", Mimeo.

[13] Jensen, R., and M. Thursby (2001), "Proofs and Prototypes for Sale: The Licensing of University Inventions", American Economic Review, 91, 240-259.

[14] Kenney, M. and D. Patton (2009), "Reconsidering the Bayh-dole Act and the Current University Ownership Model", Research Policy, 38, 1407-1422. 
[15] Laffont, J.J. (1989), The Economics of Uncertainty and Information. The MIT Press: Cambridge, MA.

[16] Lissoni, F., P. Lotz, J. Schovsbo, and A. Treccani (2009), "Academic Patent and the Professor's Privilege: Evidence on Denmark from the KEINS Database", Science and Public Policy, 36, 595-607.

[17] Litan, R., L. Mitchell, and E.J. Reedy (2008), "Commercializing University Inventions: Alternative Approaches", in J. Lerner and S Stern (eds, Innovation Policy and the Economy. University of Chicago Press: Chicago.

[18] Lowe, R. (2006), "Who Develops a University Invention? The Impact of Tacit Knowledge and Licensing Policies", Journal of Technology Transfer, 31, 415-429.

[19] Lowe, R. and A. Ziedonis (2006), "Overoptimism and the Performance of Entrepreneurial Firms", Management Science, 52, 173-186.

[20] Macho-Stadler, I., D. Perez-Castrillo and R. Veugelers (2008), "Designing Contracts for University Spin-0ffs", Journal of Economics and Management Strategy, 17, 185-218.

[21] Mowery, D., R. R. Nelson, B. Sampat and A. Ziedonis (2004), Ivory Tower and Industrial Innovation: U.S. University-Industry Technology Transfer Before and After the Bayh-Dole Act. Stanford University: Stanford Press

[22] Mowery, D. and B. Sampat (2005), "The Bayh-Dole Act of 1980 and University Industry Technology Transfer: A Model for other OECD Governments?", The Journal of Technology Transfer, 30, 115-127.

[23] National Research Council (2010), Managing University Intellectual Property in the Public Interest The National Academy Press: Washington, D. C.

[24] Parr, R. (2007), Royalty Rates for Licensing Intellectual Property. John Wiley and Sons: New York.

[25] Rai, A. (1999), "Regulating Scientific Research: Intellectual Property Rights and the Norms of Science", Northwestern University Law Review, 94, 77-152.

[26] Rothaermel, F., S. Agung, and L. Jiang (2007), "University Entrepreneurship: A Taxonomy of the Literature", Industrial and Corporate Change, 16, 691-791.

[27] Shane, S. (2000), "Prior Knowledge and the Discovery of Entrepreneurial Opportunities", Organization Science, 11, 448-469.

[28] Stephen, T.K. (2010), "Asian Initiatives on Bayh-Dole with special Reference to India: How Do We Make it More "Asian"?", Chicago-Kent Journal of Intellectual Property, 10, 44-64. 
[29] Thursby, J. and M. Thursby (2008), "Knowledge Creation and Diffusion of Public Science with Intellectual Property Rights", in K. Maskus (ed), Intellectual Property Rights and Technical Change, Frontiers in Economics. Elsevier: New York.

[30] Thursby, J. and M. Thursby (2010), "University Licensing: Harnessing or Tarnishing Research?", in J. Lerner and S. Stern (eds), Innovation Policy and the Economy. University of Chicago Press: Chicago.

[31] Thursby, J. and M. Thursby (2000), "Industry Perspectives on Licensing University Technologies: Sources and Problems," Association of University Industry Managers Journal, (2000 with Jerry Thursby), 9-22. Reprinted in Industry and Higher Education (August 2001)

[32] Thursby, J., R. Jensen and M. Thursby (2001), "Objectives, Characteristics and Outcomes of University Licensing: A Survey of Major U.S. Universities", Journal of Technology Transfer, 26, 59-72.

[33] Valentin, F., R. L. Jensen (2007), "Effects on academia-Industry collaboration of extending university property rights", Journal of Technology Transfer, 32, 251-276

[34] Verspagen, B. (2006), "University Research, Intellectual Property Rights and European Innovation Systems", Journal of Economic Surveys, 20, 607-632.

[35] Washburn, J. (2008), University Inc.: The Corporate Corruption of Higher Education. Basic Books: New York. 


\section{Appendix}

\section{US system: the university owns the invention}

\section{a. TTO licenses to startup}

Expected profit from startup:

$$
\Pi_{S}^{U S}=B\left(e_{S}^{U S}\right)^{\lambda} q_{S} \pi-c
$$

where $e_{S}^{U S} \in(0,1)$ is inventor effort from startup under the US system, $q_{S}$ captures commercialization skills in the startup, $\pi$ is net sales and $c$ is a fixed development cost.

Inventor income

$$
\begin{aligned}
I_{S}^{U S} & =s^{U S}+\sigma\left[B\left(e_{S}^{U S}\right)^{\lambda} q_{S} \pi-c-r_{S}^{U S}\left(B\left(e_{S}^{U S}\right)^{\lambda} q_{S} \pi\right)\right]+\alpha r_{S}^{U S}\left(B\left(e_{S}^{U S}\right)^{\lambda} q_{S} \pi\right) \\
& =s^{U S}+\sigma\left[B\left(e_{S}^{U S}\right)^{\lambda} q_{S} \pi-c\right]+(\alpha-\sigma) r_{S}^{U S} B\left(e_{S}^{U S}\right)^{\lambda} q_{S} \pi
\end{aligned}
$$

where $s^{U S}$ is the inventor's university salary in the US, $\alpha$ is inventor's share of license revenue, and $r_{S}^{U S}$ is royalty rate charged to the startup under the US system

Inventor utility

$$
U_{S}^{U S}=\ln \left(s^{U S}+\sigma\left[B\left(e_{S}^{U S}\right)^{\lambda} q_{S} \pi-c\right]+(\alpha-\sigma) r_{S}^{U S} B\left(e_{S}^{U S}\right)^{\lambda} q_{S} \pi\right)+A \ln \left(T-\gamma e_{S}^{U S}\right)
$$

FOC $e_{S}^{U S}$

$$
\frac{\lambda B\left(e_{S}^{U S}\right)^{\lambda-1} q_{S} \pi\left(\sigma+(\alpha-\sigma) r_{S}^{U S}\right)}{s^{U S}+\sigma\left[B\left(e_{S}^{U S}\right)^{\lambda} q_{S} \pi-c\right]+(\alpha-\sigma) r_{S}^{U S} B\left(e_{S}^{U S}\right)^{\lambda} q_{S} \pi}-A \frac{\gamma}{T-\gamma e_{S}^{U S}}=0
$$

\section{b. TTO licenses to an established firm}

Expected profit:

$$
\Pi_{F}^{U S}=B\left(e_{F}^{U S}\right)^{\lambda} q_{F} \pi-c
$$

where $e_{F}^{U S} \in(0,1)$ is inventor effort in firm under the US system, $q_{F}$ denotes commercialization skills in the established firm.

Inventor income

$$
I_{F}^{U S}=s^{U S}+\alpha r_{F}^{U S}\left(B\left(e_{F}^{U S}\right)^{\lambda} q_{F} \pi\right)
$$

Inventor utility 


$$
U_{F}^{U S}=\ln \left(s^{U S}+\alpha r_{F}^{U S}\left(B\left(e_{F}^{U S}\right)^{\lambda} q_{F} \pi\right)\right)+A \ln \left(T-\gamma e_{F}^{U S}\right)
$$

FOC $e_{F}^{U S}$

$$
\frac{\lambda \alpha r_{F}^{U S} B\left(e_{F}^{U S}\right)^{\lambda-1} q_{F} \pi}{s^{U S}+\alpha r_{F}^{U S}\left(B\left(e_{F}^{U S}\right)^{\lambda} q_{F} \pi\right)}-A \frac{\gamma}{T-\gamma e_{F}^{U S}}=0
$$

\section{TTO's choice of licensee}

Expected license revenue to the TTO if licensee is an established firm

$$
R_{F}=(1-\alpha) r_{F}^{U S}\left(B\left(e_{F}^{U S *}\right)^{\lambda} q_{F} \pi\right)-v k
$$

where $(1-\alpha)$ is the TTO's share of license revenue and $e_{F}^{U S *}$ is optimal inventor effort, $k$ is search cost for an individual researchers of finding a firm, and $v$ is the share of the cost that the TTO incurs. If the TTO has increasing returns to scale in searching, informational advantages or skills, that corresponds to $v<1$.

Expected license revenue to the TTO if the licensee is a startup

$$
R_{S}=(1-\alpha) r_{S}^{U S}\left(B\left(e_{S}^{U S *}\right)^{\lambda} q_{S} \pi\right)
$$

The TTO chooses to license to a startup if

$$
R_{S}>R_{F}
$$

or, defining $\Omega$ as:

$$
\Omega=(1-\alpha) r_{S}^{U S}\left(B\left(e_{S}^{U S *}\right)^{\lambda} q_{S} \pi\right)-(1-\alpha) r_{F}^{U S}\left(B\left(e_{F}^{U S *}\right)^{\lambda} q_{F} \pi\right)+v k
$$

the condition can be stated as

$$
\Omega>0
$$

\section{Swedish system: professor privilege}

\section{a. Inventor does a startup}

Expected profit

$$
\Pi_{S}^{S W E}=B\left(e_{S}^{S W E}\right)^{\lambda} q_{S} \pi-c
$$

where $e_{S}^{S W E} \in(0,1)$ is inventor effort from startup under the Swedish system. 
Inventor income

$$
I_{S}^{S W E}=s^{S W E}+\sigma\left(B\left(e_{S}^{S W E}\right)^{\lambda} q_{S} \pi-c\right)
$$

where $s^{S W E}$ is inventor's university salary in Sweden.

Inventor utility

$$
U_{S}^{S W E}=\ln \left(s^{S W E}+\sigma\left(B\left(e_{S}^{S W E}\right)^{\lambda} q_{S} \pi-c\right)\right)+A \ln \left(T-\gamma e_{S}^{S W E}\right)
$$

FOC $e_{S}^{S W E}$

$$
\frac{\lambda \sigma B\left(e_{S}^{S W E}\right)^{\lambda-1} q_{S} \pi}{s^{S W E}+\sigma\left(B\left(e_{S}^{S W E}\right)^{\lambda} q_{S} \pi-c\right)}-A \frac{\gamma}{T-\gamma e_{S}^{S W E}}=0
$$

\section{b. Inventor licenses to an established firm}

Expected profit

$$
\Pi_{F}^{S W E}=B\left(e_{F}^{S W E}\right)^{\lambda} q_{F} \pi-c
$$

where $e_{F}^{S W E} \in(0,1)$ is inventor effort from licensing to an established firm under the Swedish system.

Inventor income

$$
I_{F}^{S W E}=s^{S W E}+r_{F}^{S W E}\left(B\left(e_{F}^{S W E}\right)^{\lambda} q_{F} \pi\right)-k
$$

where $k$ is a fixed cost of searching for a licensee.

Inventor utility

$$
U_{F}^{S W E}=\ln \left(s+r_{F}^{S W E}\left(B\left(e_{F}^{S W E}\right)^{\lambda} q_{F} \pi\right)-k\right)+A \ln \left(T-\gamma e_{F}^{S W E}\right)
$$

FOC $e_{F}^{S W E}$

$$
\frac{\lambda r_{F}^{S W E} B\left(e_{F}^{S W E}\right)^{\lambda-1} q_{F} \pi}{s+r_{F}^{S W E}\left(B\left(e_{F}^{S W E}\right)^{\lambda} q_{F} \pi\right)-k}-A \frac{\gamma}{T-\gamma e_{F}^{S W E}}=0
$$

